\title{
ЭКОЛОГИЯ
}

И ПРИРОДОПОЛЬЗОВАНИЕ

DOI: https://doi.org/10.15688/jvolsu11.2017.1.3

UDC 502.4(470.46)

LВС 28.088л64

\section{SPECIALLY PROTECTED AREAS AND ECOLOGICAL TOURIST ACTIVITY}

\author{
Aleksandr N. Barmin \\ Astrakhan State University, Astrakhan, Russian Federation \\ Stanislav B. Glagolev \\ Bogdinsko-Baskunchakskiy State Natural Reserve, Akhtubinsk, Russian Federation \\ Denis S. Grachev \\ Astrakhan State University, Astrakhan, Russian Federation \\ Mikhail M. Iolin \\ Astrakhan State University, Astrakhan, Russian Federation
}

\begin{abstract}
Ecological tourism in especially protected natural territories has a high potential for their development. The ecotourism is designed to satisfy, on the one hand, the human need for communication with the nature, studying the culture, and, on the other hand, to solve economic and nature protection problems of the remote $\approx$ regions. Tendencies of development of ecotourism are determined by the World Tourism Organization (UNWTO) $\vec{\sim}$ according to which forecasting this type of tourism is among the main strategic directions of world development for $\therefore$ the period till 2020. According to expert evaluations, the quantity of the population anxious with the state of nature, continuously grows. Ecological tourism and its principles reflect a concept of sustainable development: preserving the ethnographic status of the entertaining territory, preserving the entertaining natural territories biological diversity; increasing the level of economic stability and ecological culture of participants ecological and tourist activities. This industry is capable to create outer positive effects: it doesn't lead to physical destruction of biological resources; it assumes growth of educational level of tourists and the population of the host country; it $\overrightarrow{-}$ gives the chance of real attraction of the equity for development of reserves. The rich natural heritage, a variety of flora and fauna represent unique opportunities for development of ecotourism in Russia.
\end{abstract}

Key words: ecological tourism, reserve, management, development, economic profit.

УДК 502.4(470.46)

БКК $28.088 л 64$

\section{ОСОБО ОХРАНЯЕМЫЕ ПРИРОДНЫЕ ТЕРРИТОРИИ И ЭКОЛОГО-ТУРИСТИЧЕСКАЯ ДЕЯТЕЛЬНОСТЬ}

\author{
Александр Николаевич Бармин
}

Астраханский государственный университет, г. Астрахань, Российская Федерация 


\title{
ЭКОЛОГИЯ И ПРИРОДОПОЛЬЗОВАНИЕ
}

\section{Станислав Борисович Глаголев}

Государственный природный заповедник «Богдинско-Баскунчакский», г. Ахтубинск, Российская Федерация

\section{Денис Сергеевич Грачев}

Астраханский государственный университет, г. Астрахань, Российская Федерация

\section{Михаил Михайлович Иолин}

Астраханский государственный университет, г. Астрахань, Российская Федерация

\begin{abstract}
Аннотация. Экологический туризм на особо охраняемых природных территориях является перспективным и представляет большой потенциал для их развития. Экологический туризм и его принципы отражают концепцию устойчивого развития: сохранение этнографического статуса рекреационной территории; повышение экологической культуры участников экотуристической деятельности; сохранение биологического разнообразия рекреационных природных территорий; повышение уровня экономической устойчивости регионов.
\end{abstract}

Ключевые слова: экологический туризм, заповедник, управление, развитие, экономическая выгода.

В 70-80-е гг. XX в. на мировом рынке туристских услуг появился особый продукт под названием «есо-tour»- экологический туризм (экотуризм). Этот вид туризма связан с организацией отдыха в мало измененных естественно-природных комплексах. Экотуризм призван, с одной стороны, удовлетворить человеческую потребность в общении с природой, изучении и познании природы и культуры, a c другой - решить экономические и природоохранные проблемы отдаленных регионов $[2 ; 3 ; 12 ; 16 ; 20]$. Можно назвать как минимум две основные причины активного развития экотуризма. Во-первых, сейчас во всех регионах мира главной задачей является сохранение окружающей среды; во-вторых, люди по причинам урбанизации стали испытывать возрастающую потребность в общении с природой. С развитием экотуризма связаны смены моделей природопользования, ориентированных не только на экономическое и социальное развитие, но и на охрану природного и культурного достояния $[4 ; 6 ; 11 ; 18 ; 24]$. Задача экотуризма - научить людей любить и уважать природу, понимать ее законы, относиться к ней бережно.

Эта отрасль способна создавать внешние положительные эффекты: не приводит к физическому уничтожению биологических ресурсов; предполагает рост образовательного уровня туристов и населения принимающей страны; дает возможность реального привлечения капитала для развития заповедников $[9 ; 13 ; 19]$.
Тенденции развития экотуризма определены Всемирной туристской организацией (ЮНВТО), по прогнозам которой этот вид туризма входит в число основных стратегических направлений мирового развития на период до 2020 года. Согласно экспертным оценкам количество населения, озабоченного состоянием природы, непрерывно растет. Основной поток экотуристов в мире составляют жители промышленно развитых стран, интересующиеся природой, которая охраняется в заповедниках, национальных парках, заказниках.

Богатоеприродное наследие, разнообразие флоры и фауны представляют уникальные возможности для развития экотуризма в России. В настоящее время в России экотуризм в заповедниках разрешен законодательно ( Федеральный закон от 14 марта 1995 г. № 33 Ф3 «Об особо охраняемых природных территориях») [22].

Его доля в общей структуре российского туристского рынка пока незначительна (около $1 \%$ ). Серьезным ограничением для экотуризма является высокая чувствительность многих экосистем России к антропогенным воздействиям. При создании и улучшении условий для экотуризма в перспективных регионах, соблюдении требований к охране окружающей среды это направление туризма может обеспечить дополнительный туристский поток свыше 0,3 млн чел. в год.

В Астраханской области экологический туризм в особо охраняемых природных территориях (ООПТ) активно развивается. По 
данным территориального органа Федеральной службы государственной статистики по Астраханской области, количество посетителей заповедников в период с 2003 по 2016 г. в среднем составляет 7514 человек и основной вклад в развитие экологического туризма на особо охраняемых природных территориях области вносит Богдинско-Баскунчакский государственный природный заповедник (более 80 \%) (см. рисунок) [7; 14].

Богдинско-Баскунчакский государственный природный заповедник был образован в 1997 г. (площадь 18478 га) [16]. Ландшафтный комплекс заповедника обладает уникальным и экзотичным природным комплексом, являющимся эталоном полупустынных ландшафтов Юга России [14].

В настоящее время в Богдинско-Баскунчакском заповеднике разработаны следующие экологические маршруты, пролегающие по территории государственного природного заповедника «Богдинско-Баскунчакский» и одноименного заказника [21].

Экскурсионный маршрут № 1: устье балки Кордонная; Суриковская балка; гора Большое Богдо; озеро Баскунчак; урочище Шарбулак.

Экскурсионный маршрут № 2: балка Кордонная; Поющие скалы; урочище Шарбулак; озеро Баскунчак; урочище Кривая Лощина.

Экскурсионный маршрут № 3: Поющие скалы; гора Большое Богдо; озеро Бас- кунчак; урочище Шарбулак; пески Щигреты; Суриков сад.

Экскурсионный маршрут № 4: Поющие скалы; гора Большое Богдо; озеро Баскунчак; урочище Шарбулак; Зеленый сад.

Экскурсионный маршрут № 5: озеро Баскунчак; балка Кордонная; Поющие скалы; гора Большое Богдо; Зеленый сад.

Экскурсионный маршрут № 6: пещера Баскунчакская; озеро Карасун; грейдер; урочище Тазбулак.

Экскурсионный маршрут № 7: пещера Баскунчакская; балка Белая; озеро Карасун; река Горькая; урочище Карагуз [14].

Экскурсионный маршрут № 8: балка Пещерная; пещера Баскунчакская; озеро Баскунчак; пещера Метро; пещера Органная [14].

Экскурсионный маршрут № 9: озеро Карасун; озеро Горькое; река Горькая; урочище Карагуз; урочище Вак-Тау [14].

Экскурсионный маршрут № 10: балка Родниковая; пещера Шаровская-1; пещера Шаровская-2; пещера Шаровская-3; пещера Баскунчакская [14].

К сожалению, до настоящего времени не все перечисленные маршруты по ряду технических проблем являются действующими. Активными являются только первые три маршрута. Необходимо учитывать, что на двух маршрутах требуется проезд по территории государственного природного заказника «Богдинско-Баскунчакский».

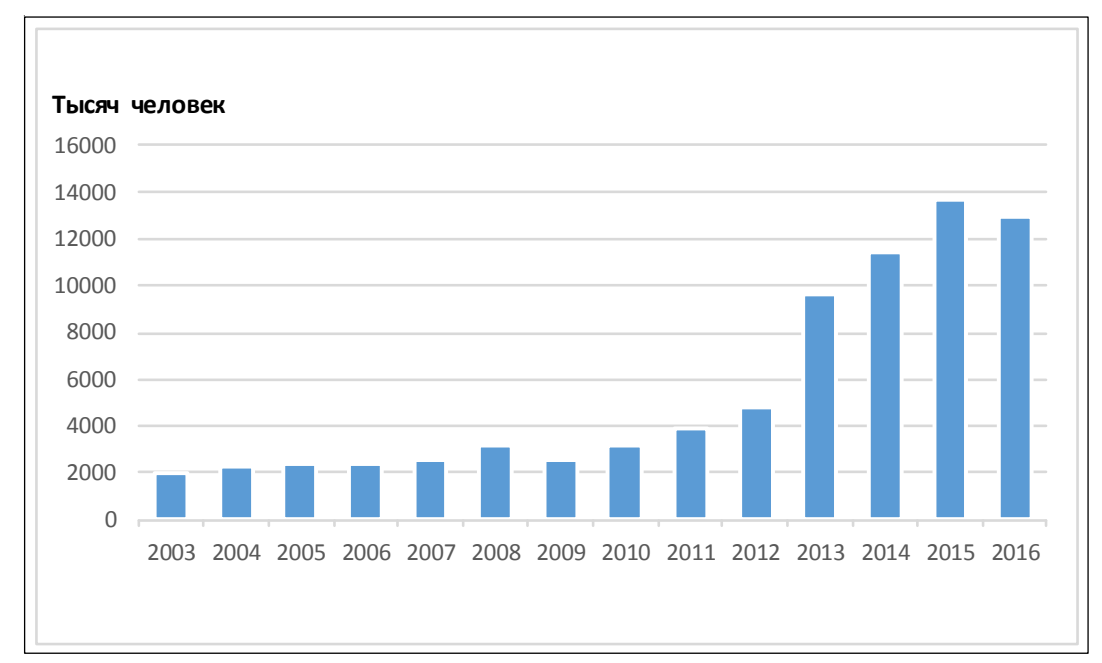

Эколого-просветительская и туристическая деятельность на территории Богдинско-Баскунчакского государственного природного заповедника

Примечание. Данные 2016 г. за период 01.01-30.09. 


\section{ЭКОЛОГИЯ И ПРИРОДОПОЛЬЗОВАНИЕ}

Нагрузка на маршруты неравномерна. Основное количество туристов - около $90 \%$ приходится на маршрут № 2, 8 \% - на маршрут № 1 и лишь $2 \%$ - на кольцевой автомобильный маршрут № 3.

Для беспрепятственного прохождения маршрутов предлагается следующее: при реализации маршрутов с необходимым проездом по территории заказника перечислять в его фонд $10 \%$ стоимости экскурсии; при посещении одной точки осмотра - $20 \%$; двух точек осмотра $-40 \%$; трех точек осмотра $-60 \%$ и при посещении маршрута, полностью расположенного на территории заказника, -80 \%, так как организация маршрутов, экскурсионное сопровождение и иные расходы ложатся на заповедник. Если на территории заповедника и заказника будут созданы и введены в эксплуатацию все разработанные маршруты, то экономический эффект с учетом издержек составит более 200 тыс. рублей.

Заповедник, являясь государственным учреждением, финансируется за счет средств федерального бюджета, а также за счет поступлений из внебюджетных и иных не запрещенных законодательством источников, в том числе доходов от собственной деятельности (табл. 1).

Наблюдается тенденция изменения процентного соотношения бюджетного и внебюд- жетного финансирования относительно совокупного бюджета заповедника: если в 2007 г. доход от самостоятельной деятельности и прочие безвозмездные поступления составляли лишь $5 \%$ от всех средств заповедника, то к 2016 г. доход вырос до 15,5 \%, что свидетельствует об активной деятельности, проводимой заповедником.

Основным видом деятельности, приносящим доход и формирующим внебюджетные поступления, является экологический туризм [5]. Экскурсионная деятельность имеет сезонный характер и проводится с марта по ноябрь. Наибольшее количество посетителей приходится на конец апреля - начало мая и конец августа начало сентября. В указанные периоды климатические условия наиболее комфортны и предпочтительны для посещения изучаемого объекта [8]. Соответственно доход от рассматриваемого вида деятельности также неравномерно распределен по времени и объему поступлений. Целевой аудиторией в весенний период в основном являются школьники и клиенты туристических фирм; июль-август - студенты и самостоятельные посетители; август-сентябрь - клиенты туристических фирм. Иностранные туристы составляют $0,5 \%$ от общего потока, 2 группы в год - около 10-15 человек [6].

В 2016 г. установлены следующие размеры платы за услуги, связанные с посеще-

Таблица 1

Финансирование государственного природного заповедника «Богдинско-Баскунчакский»

\begin{tabular}{|c|c|c|c|c|c|c|c|}
\hline \multicolumn{2}{|c|}{$\begin{array}{c}\text { Формирование } \\
\text { совокупного бюд- } \\
\text { жета ФГБУ }\end{array}$} & \multirow{2}{*}{$\begin{array}{c}\text { Доход из } \\
\text { государст- } \\
\text { венного } \\
\text { бюджета } \\
3815,8 \\
\end{array}$} & \multirow{2}{*}{$\begin{array}{c}\text { Субсидии на } \\
\text { иные цели } \\
-\end{array}$} & \multirow{2}{*}{$\begin{array}{l}\text { Внебюджет- } \\
\text { ные средства } \\
203,2\end{array}$} & \multirow{2}{*}{$\begin{array}{c}\text { Доход от } \\
\text { услуг, оказы- } \\
\text { ваемых уч- } \\
\text { реждением } \\
197,7\end{array}$} & \multirow{2}{*}{\begin{tabular}{|c|}
$\begin{array}{c}\text { Прочие без- } \\
\text { возмездные } \\
\text { поступления }\end{array}$ \\
5,5 \\
\end{tabular}} & \multirow{2}{*}{$\begin{array}{c}\text { Общий } \\
\text { доход } \\
4222,2\end{array}$} \\
\hline 2007 & тыс. руб. & & & & & & \\
\hline 2007 & $\%$ & 90,37 & - & 4,81 & 4,68 & 0,14 & 100 \\
\hline \multirow{2}{*}{2009} & тыс. руб. & 5923,8 & - & 760,2 & 307,2 & 453,0 & 7444,2 \\
\hline & $\%$ & 79,57 & - & 10,20 & 4,15 & 6,08 & 100 \\
\hline \multirow{2}{*}{2011} & тыс. руб. & 9495,8 & - & 746,8 & 744,8 & 2 & 10989,4 \\
\hline & $\%$ & 86,43 & - & 6,79 & 6,77 & 0,01 & 100 \\
\hline \multirow{2}{*}{2012} & тыс. руб. & 9205,4 & - & 1544,5 & 971,5 & 573,0 & 12294,4 \\
\hline & $\%$ & 74,87 & - & 12,56 & 7,9 & 4,67 & 100 \\
\hline \multirow{2}{*}{2013} & тыс. руб. & 9955,7 & - & 1270,9 & 1265,9 & 5,0 & 12497,5 \\
\hline & $\%$ & 76,66 & - & 10,16 & 10,5 & 0,04 & 100 \\
\hline \multirow{2}{*}{2014} & тыс. руб. & 9241,6 & 1000,0 & 2129,9 & 1830,2 & 299,7 & 14501,4 \\
\hline & $\%$ & 63,75 & 6,89 & 14,68 & 12,62 & 2,06 & 100 \\
\hline \multirow{2}{*}{2015} & тыс. руб. & 13136,4 & 1000,0 & 2258,0 & 2242,9 & 15,1 & 18652,4 \\
\hline & $\%$ & 70,42 & 5,36 & 12,3 & 12,02 & 0,08 & 100 \\
\hline \multirow{2}{*}{2016} & тыс. руб. & 8851,4 & 1400,0 & 2313,2 & 2312,3 & 0,9 & 14872,8 \\
\hline & $\%$ & 59,51 & 9,41 & 15,54 & 15,53 & 0,01 & 100 \\
\hline
\end{tabular}


нием экологических маршрутов на территории заповедника: посещение экологических экскурсионно-туристических маршрутов (табл. 2).

Одним из значимых моментов в развитии Богдинско-Баскунчакского заповедника является открытие для посетителей Музея природы в мае 2010 года. Это способствовало расширению эколого-просветительской деятельности и привлечению дополнительных денежных средств (табл. 2).

Средний ежегодный доход от экологического туризма возрастает с каждым годом: если в 2007 г. он составлял 197,7 тыс. руб. (5\%), то в 2016 г. он составил 2 312,3 тыс. руб., что равняется $15,5 \%$ от всего бюджета учреждения за год и $100 \%$ от поступлений из внебюджетных источников.

В настоящее время для улучшения и дальнейшего развития инфраструктуры БогдинскоБаскунчакского заповедника разработана программа по расширению предлагаемых услуг.

1. С 2013 г. функционирует эколого-научный центр на территории участка «Зеленый сад» с целью ведения эколого-просветительской и научной работы. Данный комплекс строений может использоваться в качестве коммерческой составляющей (размещение и проживание ученых, туристов, проведение научных семинаров, практик студентов, презентаций и т. д.).

2. В 2014 г. были созданы 3 орнитологические смотровые площадки в естественных условиях для слежения за хищными птицами. Одна из площадок была обустроена с фото- и видеофиксацией с применением альтернативных источников энергии (солнечные батареи).

3. В 2015 г. была обустроена энтомологическая площадка для наблюдений за энтомофауной с помощью ловушек Мерике. Данная площадка размещается на территории участка «Зеленый сад». Энтомологическое наблюдение должно сопровождаться рассказом специалиста и возможным фотографированием редких экземпляров насекомых [1].

4. В настоящее время является актуальным создание электронной программы, включающей путеводитель по экскурсионным маршрутам, и аренда устройств для ее воспроизводства, предназначенных для индивидуальных посетителей или малых групп без экскурсовода, в том числе на иностранном языке $[10 ; 15 ; 17 ; 23]$.

Все перечисленные мероприятия направлены не только на увеличение привлекательности, но и на сбалансированность между туризмом и охраной окружающей среды, способствующих сохранению природных ресурсов и экономической стабильности не только ООПТ, но и прилегающих территорий.

Развитие экотуризма на территории Acтраханской области открывает долгосрочные перспективы для устойчивого социально-экономического развития региона.

\section{СПИСОК ЛИТЕРАТУРЫ}

1. Амосов, П. Н. Фауна позвоночных животных заповедника «Богдинско-Баскунчакский» / П. Н. Амосов. - Волгоград : Царицын, 2010. - С. 22-25.

Таблица 2

Стоимость предоставления услуг по посещению туристами государственного Богдинско-Баскунчакского природного заповедника в 2013-2016 гг.

\begin{tabular}{|c|l|c|}
\hline № п/п & \multicolumn{1}{|c|}{ Наименование услуг } & Цена, руб. \\
\hline 1 & $\begin{array}{l}\text { Экскурсия по экологическому маршруту № 1, № 2 заповедника для } \\
\text { индивидуального посещения с проездом на личном транспорте: } \\
\text { взрослый билет } \\
\text { детский билет (с 7 до 14 лет) }\end{array}$ & 180 \\
\hline 2 & Экскурсия по экологическому маршруту № 3 & 600 \\
\hline 3 & Посещение музея заповедника & 70 \\
\hline 4 & $\begin{array}{l}\text { Сопровождение автотранспортом заповедника по экологическому } \\
\text { маршруту № 2 }\end{array}$ & 500 \\
\hline 5 & $\begin{array}{l}\text { Учебная экскурсия по заповеднику при проведении полевых прак- } \\
\text { тик студентов (с экскурсанта) }\end{array}$ & 10000 \\
\hline 6 & $\begin{array}{l}\text { Проведение профессиональной фото- и видеосессии сторонними } \\
\text { организациями (день) }\end{array}$ & \multicolumn{1}{|l}{} \\
\hline
\end{tabular}


2. Богдинско-Баскунчакский заповедник и его роль в сохранении биоразнообразия севера Астраханской области. Перспективы экологического туризма : сб. науч. ст. - Астрахань : Изд-во АГТУ, 2004. - C. 100-105.

3. Бармин, А. Н. Анализ ландшафтного разнообразия административного образования с целью оптимизации его организации и управления (на примере Ахтубинского района Астраханской области) / А. Н. Бармин, М. М. Иолин, М. А. Стебенькова // Геология, география и глобальная энергия. - 2006. - № 3. - С. 30-34.

4. Бармин, А. Н. Региональные проблемы развития сети особо охраняемых природных территорий / А. Н. Бармин, А. С. Ермолина, А. В. Бузланов // Геология, география и глобальная энергия. 2006. - № 5. - С. 58-60.

5. Бармин, А. Н. Современные вопросы природопользования в Ахтубинском районе Астраханской области / А. Н. Бармин, М. М. Иолин, М. А. Стебенькова // Геология, география и глобальная энергия. -2006 . -№ 1. - С. 189-196.

6. Дедов, С. В. Особенности экологического туризма в современных экономических условиях / С. В. Дедов, С. В. Демин // Вестник Воронежского государственного университета. Серия «География. Геоэкология». - 2007. - № 1. - С. 17-43.

7. Ермолина, А. С. Научно-методологическое обоснование развития экологического туризма на территории Астраханской области / А. С. Ермолина, А. Н. Бармин, М. М. Иолин // Естественные науки. - 2011. - № 2. - С. 75-80.

8. Ермолина, А. С. Основы и перспективы развития природного туризма / А. С. Ермолина, М. М. Иолин, А. Н. Бармин // Геология, география и глобальная энергия. - 2011. - № 2. - С. 261-266.

9. Иолин, Н. М. Туризм и особо охраняемые природные территории / Н. М. Иолин, А. Н. Бармин, М. М. Иолин // Южно-Российский вестник геологии, географии и глобальной энергии. - 2006. № 6. - С. 302-304.

10. Колотухин, А. Ю. ГИС-технологии и перспективы их использования для экологического туризма на примере Богдинско-Баскунчакского заповедника / А. Ю. Колотухин, Е. Г. Русакова // Естественные науки, 2014. - № 1. - С. 16-20.

11. Михненко, М. Н. Особо охраняемые территории как объект экологического туризма / М. Н. Михненко, А. Н. Бармин // Южно-Российский вестник геологии, географии и глобальной энергии. -2005 . - № 2. - С. 98-100.

12. Никифорова, Л. Ю. Экологический туризм как направление развития экономики региона / Л. Ю. Никифорова // Экономика и управление. 2009. - № 2 (5). - С. 130-132.

13. Оптимизация управления особо охраняемыми природными территориями (на примере Ac- траханской области) / А. С. Ермолина, А. Н. Бармин, М. М. Иолин, Р. В. Кондрашин // Естественные и технические науки. - 2010. - № 1. - С. 210-214.

14. Особо охраняемые природные территории Ахтубинского района Астраханской области / С. Б. Глаголев, М. А. Стебенькова, А. Н. Бармин, М. Н. Михненко // Геология, география и глобальная энергия. - 2005. - № 2. - С. 159-162.

15. Особо охраняемые природные территории как объект для создания геоинформационной системы / А. Ю. Колотухин, А. Н. Бармин, К. М. Некрасов [и др.] // Геоинформационное пространство в регионах России : материалы VII Bсерос. науч.практ. конф. - Воронеж : Научная книга, 2015. C. 57-61.

16. Особо охраняемые природные территории: проблемы, решения, перспективы : коллектив. моногр. / А. Н. Бармин, А. С. Ермолина, М. М. Иолин [и др.]. - Астрахань : АЦТ, 2010. - 312 с.

17. Принципы организации комплексных ГИС особо охраняемых природных территорий / А. Ю. Колотухин, А. Н. Бармин, А. В. Синцов, М. В. Валов // Геология. География и глобальная энергия. -2016. - № 3. - С. 61-70.

18. Развитие эколого-туристической деятельности на особо охраняемых природных территориях. Познавательный туризм на ООПТ: теория, практика и бизнес : материалы Междунар. науч.-практ. конф. - Иркутск : Изд-во ИГУ, 2013. - 353 с.

19. Состояние и многолетние изменения природной среды на территории Богдинского-Баскунчакского : коллектив. моногр. / П. Н. Амосов, А. В. Александрова [и др.] ; ред. И. Н. Сафронова, П. И. Бухарицин, А. Н. Бармин. - Волгоград : Царицын, 2012. $360 \mathrm{c}$.

20. Тимофеева, П. И. Экономические факторы устойчивого развития рекреации (на примере экологического туризма) / П. И. Тимофеева // Известия Санкт-Петербургского университета экономики и финансов. - 2007. - № 4. - С. 182-184.

21. Туристические маршруты Богдинско-Баскунчакского заповедника и Богдинско-Баскунчакского заказника / А. Ю. Колотухин, А. Н. Бармин, А. С. Ермолина [и др.] // Свидетельство о государственной регистрации базы данных № 2012620976, зарегистрировано в реестре баз данных 21.09.2012.

22. Федеральный закон «Об особо охраняемых природных территориях» от 14 марта 1995 г. № 33Ф3 : (ред. от 28 дек. 2016 г.). - Доступ из справ.информ. портала «ГАРАНТ».

23. Электронная база данных в экологическом туризме / А. Ю. Колотухин, А. Н. Бармин, Д. С. Бессмельцев, В. А. Иванов // Туризм и рекреация: инновации и ГИС-технологии : материалы VI Междунар. науч.-практ. конф. - Астрахань : Техноград, 2013. - C. 53-56. 
24. Экологическое состояние территории Ахтубинского района Астраханской области при современном природопользовании / С. Б. Глаголев, М. А. Стебенькова, А. Н. Бармин, М. М. Иолин // Геология, география и глобальная энергия. - 2005. № 2. - C. 36-39.

\section{REFERENCES}

1. Amosov P.N. Fauna pozvonochnykh zhivotnykh zapovednika "Bogdinsko-Baskunchakskiy» [Fauna of Vertebrate Animals of the BogdinskoBaskunchakskyReserve]. Volgograd, Tsaritsyn Publ., 2010, pp. 22-25.

2. Bogdinsko-Baskunchakskiy zapovednik $i$ ego rol v sokhranenii bioraznoobraziya severa Astrakhanskoy oblasti. Perspektivy ekologicheskogo turizma: sb. nauch. st. [BogdinskoBaskunchaksky Reserve and Its Role in Preservation of Biodiversity of the North of the Astrakhan Region. Prospects for Ecological Tourism. Collected Articles]. Astrakhan, Izd-vo AGTU, 2004, pp. 100-105.

3. Barmin A.N., Iolin M.M., Stebenkova M.A. Analiz landshaftnogo raznoobraziya administrativnogo obrazovaniya s tselyu optimizatsii ego organizatsii i upravleniya (na primere Akhtubinskogo rayona Astrakhanskoy oblasti) [Analysis of the Landscape Diversity of Administrative Education for the Purpose of Optimizing Its Organization and Management (on the Example of the Akhtuba District of the Astrakhan Region)]. Geologiya, geografiya $i$ globalnaya energiya, 2006, no. 3, pp. 30-34.

4. Barmin A.N., Ermolina A.S., Buzlanov A.V. Regionalnye problemy razvitiya seti osobo okhranyaemykh prirodnykh territoriy [Regional Problems of Development of a Network of Specially Protected Natural Areas]. Geologiya, geografiya $i$ globalnaya energiya, 2006, no. 5, pp. 58-60.

5. Barmin A.N., Iolin M.M., Stebenkova M.A. Sovremennye voprosy prirodopolzovaniya $\mathrm{V}$ Akhtubinskom rayone Astrakhanskoy oblasti [Modern Problems of Nature Management in the Akhtuba District of the Astrakhan Region]. Geologiya, geografiya i globalnaya energiya, 2006, no. 1, pp. 189-196.

6. Dedov S.V., Demin S.V. Osobennosti ekologicheskogo turizma $\mathrm{V}$ sovremennykh ekonomicheskikh usloviyakh [Features of Ecotourism in Current Economic Conditions]. Vestnik Voronezhskogo gosudarstvennogo universiteta. Seriya «Geografiya. Geoekologiya», 2007, no. 1, pp. 17-43.

7. Ermolina A.S., Barmin A.N., Iolin M.M. Nauchno-metodologicheskoe obosnovanie razvitiya ekologicheskogo turizma na territorii Astrakhanskoy oblasti [Scientific and Methodological Substantiation of Ecological Tourism Development on the Territory of the Astrakhan Region]. Estestvennye nauki, 2011, no. 2 , pp. 75-80.

8. Ermolina A.S., Iolin M.M., Barmin A.N. Osnovy i perspektivy razvitiya prirodnogo turizma [Bases and Prospects for the Development of Natural Tourism]. Geologiya, geografiya i globalnaya energiya, 2011, no. 2, pp. 261-266.

9. Iolin N.M., Barmin A.N., Iolin M.M. Turizm i osobo okhranyaemye prirodnye territorii [Tourism and Specially Protected Natural Territories]. YuzhnoRossiyskiy vestnik geologii, geografii i globalnoy energii, 2006, no. 6, pp. 302-304.

10. Kolotukhin A.Yu., Rusakova E.G. GIStekhnologii i perspektivy ikh ispolzovaniya dlya ekologicheskogo turizma na primere BogdinskoBaskunchakskogo zapovednika [GIS-Technologies and Prospects of Their Use for Ecological Tourism by the Example of the Bogdino-Baskunchak Reserve]. Estestvennye nauki, 2014, no. 1, pp. 16-20.

11. Mikhnenko M.N., Barmin A.N. Osobo okhranyaemye territorii kak obyekt ekologicheskogo turizma [Specially Protected Areas as an Object of Ecotourism]. Yuzhno-Rossiyskiy vestnik geologii, geografii i globalnoy energii, 2005, no. 2, pp. 98-100.

12. Nikiforova L.Yu. Ekologicheskiy turizm kak napravlenie razvitiya ekonomiki regiona [Ecological Tourism as a Direction of the Region's Economy Development]. Ekonomika i upravlenie, 2009, no. 2 (5), pp. 130-132.

13. Ermolina A.S., Barmin A.N., Iolin M.M., Kondrashin R.V. Optimizatsiya upravleniya osobo okhranyaemymi prirodnymi territoriyami (na primere Astrakhanskoy oblasti) [Optimization of the Management of Specially Protected Natural Areas (on the Example of the Astrakhan Region)]. Estestvennye i tekhnicheskie nauki, 2010, no. 1, pp. 210-214.

14. Glagolev S.B., Stebenkova M.A., Barmin A.N., Mikhnenko M.N. Osobo okhranyaemye prirodnye territorii Akhtubinskogo rayona Astrakhanskoy oblasti [Specially Protected Natural Areas of the Akhtuba District of the Astrakhan Region]. Geologiya, geografiya i globalnaya energiya, 2005, no. 2, pp. 159-162.

15. Kolotukhin A.Yu., Barmin A.N., Nekrasov K.M., et al. Osobo okhranyaemye prirodnye territorii kak obyekt dlya sozdaniya geoinformatsionnoy sistemy [Specially Protected Natural Territories as an Object for the Creation of the Geoinformation System]. Geoinformatsionnoe prostranstvo v regionakh Rossii: materialy VII Vseros. nauch.-prakt. konf. [Geoinformation Space in the Regions of Russia: Proceedings of the $7^{\text {th }}$ All-Russian Scientific and Practical Conference]. Voronezh, Nauchnaya kniga Publ., 2015, pp. 57-61. 


\section{ЭКОЛОГИЯ И ПРИРОДОПОЛЬЗОВАНИЕ}

16. Barmin A.N., Ermolina A.S., Iolin M.M., et al. Osobo okhranyaemye prirodnye territorii: problemy, resheniya, perspektivy: kollektiv. monogr. [Specially Protected Natural Areas: Problems, Solutions, Prospects: Collective Monograph]. Astrakhan, ATsT Publ., 2010.312 p.

17. Kolotukhin A.Yu., Barmin A.N., Sintsov A.V., Valov M.V. Printsipy organizatsii kompleksnykh GIS osobo okhranyaemykh prirodnykh territoriy [Principles of Organization of Integrated GIS of Specially Protected Natural Areas]. Geologiya. Geografiya $i$ globalnaya energiya, 2016, no. 3, pp. 61-70.

18. Razvitie ekologo-turisticheskoy deyatelnosti na osobo okhranyaemykh prirodnykh territoriyakh. Poznavatelnyy turizm na OOPT: teoriya, praktika $i$ biznes: materialy Mezhdunar. nauch.-prakt. konf. [Development of Eco-Tourism Activities in Specially Protected Natural Areas. Cognitive Tourism in Protected Areas: Theory, Practice and Business: Materials of the International Scientific and Practical Conference]. Irkutsk, Izd-vo IGU, 2013. 353 p.

19. Amosov P.N., Aleksandrova A.V. Sostoyanie $i$ mnogoletnie izmeneniya prirodnoy sredy na territorii Bogdinskogo-Baskunchakskogo: kollektiv. monogr. [Status and Long-Term Changes in the Natural Environment on the Territory of BogdinskyBaskunchak: Collective Monograph]. Volgograd, Tsaritsyn Publ., 2012. 360 p.

20. Timofeeva P.I. Ekonomicheskie faktory ustoychivogo razvitiya rekreatsii (na primere ekologicheskogo turizma) [Economic Factors of Sustainable Development of Recreation (on the Example of Ecological Tourism)]. Izvestiya SanktPeterburgskogo universiteta ekonomiki i finansov, 2007, no. 4, pp. 182-184
21. Kolotukhin A.Yu., Barmin A.N., Ermolina A.S., et al. Turisticheskie marshruty BogdinskoBaskunchakskogo zapovednika i BogdinskoBaskunchakskogo zakaznika [Tourist Routes of the Bogdino-Baskunchaksky Reserve and the BogdinoBaskunchak Wildlife Sanctuary]. Svidetelstvo o gosudarstvennoy registratsii bazy dannykh № 2012620976, zaregistrirovano $v$ reestre baz dannykh 21.09.2012 [Certificate of State Registration of the Database no. 2012620976, Registered in the Databases on September 21, 2012].

22. Federalnyy zakon «Ob osobo okhranyaemykh prirodnykh territoriyakh» ot 14.03.1995 № 33-FZ: (red. ot 28.12.2016) [The Federal Law "On Specially Protected Natural Territories" of March 14, 1995 no. 33-FL: (ed. of December 28, 2016)]. Access from GARANT Reference and Information Portal.

23. Kolotukhin A.Yu., Barmin A.N., Bessmeltsev D.S., Ivanov V.A. Elektronnaya baza dannykh $\mathrm{v}$ ekologicheskom turizme [Electronic Database in Ecological Tourism]. Turizm i rekreatsiya: innovatsii i GIS-tekhnologii: materialy VI Mezhdunar. nauch.prakt. konf. [Tourism and Recreation: Innovations and GIS Technologies: Materials of the VI International Scientific and Practical Conference]. Astrakhan, Tekhnograd Publ., 2013, pp. 53-56.

24. Glagolev S.B., Stebenkova M.A., Barmin A.N., Iolin M.M. Ekologicheskoe sostoyanie territorii Akhtubinskogo rayona Astrakhanskoy oblasti pri sovremennom prirodopolzovanii [Ecological Condition of the Territory of the Akhtuba District of the Astrakhan Region in the Modern Nature Management]. Geologiya, geografiya i globalnaya energiya, 2005, no. 2, pp. 36-39.

\section{Information about the Authors}

Aleksandr N. Barmin, Doctor of Geographical Sciences, Professor, Head of Department of Ecology of Nature Management, Land Development and Life Security, Astrakhan State University, Shaumyana Sq., 1, 414056 Astrakhan, Russian Federation, abarmin60@mail.ru.

Stanislav B. Glagolev, Candidate of Geographical Sciences, Director, Bogdinsko-Baskunchakskiy State Natural Reserve, mkrn. Melioratorov, 19-1, 416501 Akhtubinsk, Russian Federation, glagolev1972@mail.ru.

Denis S. Grachev, Student, Faculty of Geology and Geography, Astrakhan State University, Shaumyana Sq., 1, 414056 Astrakhan, Russian Federation, Krem_1992@mail.ru.

Mikhail M. Iolin, Candidate of Geographical Sciences, Associate Professor, Head of Department of Geography, Cartography and Geoinformatics, Astrakhan State University, Shaumyana Sq., 1, 414056 Astrakhan, Russian Federation, miolin76@mail.ru.

\section{Информация об авторах}

Александр Николаевич Бармин, доктор географических наук, профессор, заведующий кафедрой экологии природопользования, землеустройства и безопасности жизнедеятельности, Ас- 
траханский государственный университет, пл. Шаумяна, 1, 414056 г. Астрахань, Российская Федерация, abarmin60@mail.ru.

Станислав Борисович Глаголев, кандидат географических наук, директор, Государственный природный заповедник «Богдинско-Баскунчакский», мкрн. Мелиораторов, 19-1, 416501 г. Ахтубинск, Российская Федерация, glagolev1972@mail.ru.

Денис Сергеевич Грачев, студент геолого-географического факультета, Астраханский государственный университет, пл. Шаумяна, 1, 414056 г. Астрахань, Российская Федерация, Krem_1992@mail.ru.

Михаил Михайлович Иолин, кандидат географических наук, доцент, заведующий кафедрой географии, картографии и геоинформатики, Астраханский государственный университет, пл. Шаумяна, 1, 414056 г. Астрахань, Российская Федерация, miolin76@mail.ru. 